\title{
Futura consideranda sunt. Memoria y retórica en El Escorial, siglos XVI-XVII
}

\author{
José Luis VeGA-LOECHES \\ Universidad Complutense de Madrid. \\ Departamento de Historia del Arte II (Moderno)
}

\section{RESUMEN}

Reflexiones y consideraciones acerca de las implicaciones de la memoria como parte de la retórica en el desarrollo de la idea e imagen literaria de El Escorial en los siglos XVI y XVII, centrándonos en el papel ejercido por las descripciones jerónimas de fray José de Sigüenza y fray Francisco de los Santos.

Palabras clave: El Escorial; memoria; retórica; emblemas; siglo de Oro.

\section{Futura consideranda sunt. Memory and Rhetoric in El Escorial, sixteenth-seventeenth centuries}

\begin{abstract}
Reflections and considerations about the implications of the memory as a part of the rhetoric method in the development of the idea and image of El Escorial in sixteenth-seventeenth centuries, focusing in the descriptions of fray José de Sigüenza and fray Francisco de los Santos.
\end{abstract}

Keywords: The Escorial; memory; rhetoric; emblems; Spanish Golden Age.

"Las cosas futuras deben ser consideradas" es el lema latino que encabeza una de las estampas más peculiares y de mayor carga emblemática de El Escorial, perteneciente a la obra del poeta bohemio Daniel Meisner Thesaurus philo-politicus, publicada en Frankfurt por el impresor Eberhard Kieser entre 1624 y 1626 ${ }^{1}$ (fig. 1).

1 La obra compone una singular geografía emblemática de ciudades y edificios para cuya comprensión Meisner advierte: "Sive enim demas Emblemata, supererunt oppida sive castella et ita habebis velut argentum purum. Sive auferas oppida, restabunt Emblemata et eorum sensus mysticus", citado en PRAZ, Mario, Imágenes del barroco. Estudios de emblemática, Madrid, Siruela, 2005 (Roma, Edizioni di Storia e Letteratura, 


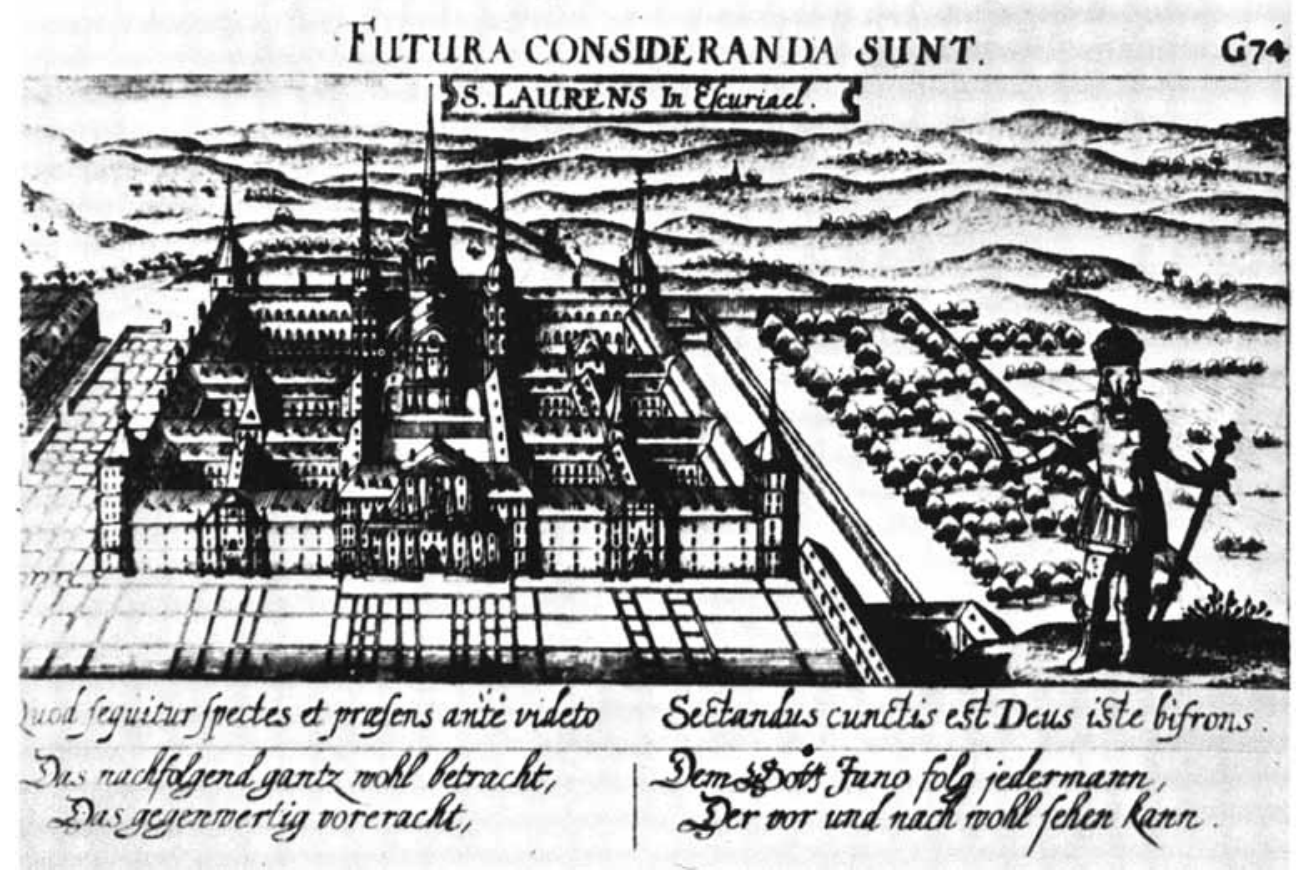

Fig. 1. Daniel Meisner, Vista emblemática de El Escorial "Futura consideranda sunt”, Frankfurt, 1624-1626.

El monumento se sitúa ligeramente desplazado a la izquierda, en su vista aérea más popular y elocuente, según el modelo codificado por Juan de Herrera en el Séptimo Diseño (1589) ya filtrado y estilizado a través del atlas de Philip Galle (1601), versión de bolsillo del más famoso de Abraham Ortelius (1591), cuyo éxito editorial daría rápidamente el aldabonazo a las pretensiones de derechos de autor del arquitecto real $^{2}$.

1964/1974), p. 63, nota 47, que traducida vendría a decir que en el caso de que los emblemas no gusten o no se comprendan: "sobrevivirán ciudades y castillos", y a la inversa, si borrásemos las vistas permanecerá "el mensaje místico de los emblemas". La estampa de El Escorial aparece de nuevo en otra impresión publicada después de la muerte de Meisner (Chomutov, 1585- Frankfurt, 1624) con el título: Libellus Novus Politicus Emblematicus Civitatum. Pars Quinta. Nüremberg, 1630. Vid. SANTIAGO PÁEZ, Elena (coord.), El Escorial en la Biblioteca Nacional. IV Centenario del Monasterio de El Escorial, catálogo de la exposición, Biblioteca Nacional (Madrid, 1984-1985), Ministerio de Cultura, 1985, pp. 268-269. La estampa ha sido estudiada por SEBASTIÁN, Santiago, "El Escorial como palacio emblemático", en Real Monasterio-Palacio de El Escorial. Estudios inéditos en el IV Centenario de la terminación de las obras, Madrid, Consejo Superior de Investigaciones Científicas, 1987, pp. 95-105.

2 Sobre la empresa editorial de Herrera, el clásico estudio de CERVERA VERA, Luis, Las Estampas y el Sumario de El Escorial por Juan de Herrera, Madrid, Colegio Oficial de Arquitectos de Madrid, Fundación Cultural C.O.A.M., 1998 (Madrid, Tecnos, 1954). Sobre la difusión posterior de la imagen de El Escorial: SANTIAGO PÁEZ, Elena, MAGARIÑOS, Juan Manuel, "El Escorial, historia de una imagen" en SANTIAGO PÁEZ, Elena (coord.) (1985), op. cit., pp. 223-366. 
A la derecha de la estampa, sobre un risco imaginario se sitúa el patrono del edificio, coronado y vestido a la romana, presenta la inconfundible fisonomía bifronte del dios Jano, aquel cuyo templo en Roma cuenta Virgilio que solamente se abría en época de guerra y quedaba cerrado por cien cerrojos en época de paz. Al templo de Jano se alude en la traducción gongorina de la Eneida de Juan Francisco de Enciso Monzón (1698) desplegando recursos persuasivos muy similares a los que fueron emblematizando el templo de Felipe II desde finales del siglo XVI: "Este que ves Alcazar soberano, es obra de Saturno, y el segundo fatiga artificiosa fue de Jano, celebrada en los terminos del mundo [...]" ${ }^{3}$

El doble rostro de Jano alude a su condición de gozne entre el pasado y el futuro, su imagen presidía las puertas y también los solsticios y las estaciones, dando nombre al primer mes del año: januarius. Jano como dios que conoce lo pasado, prevé el futuro y por tanto será la imagen emblemática de la Prudencia, así lo expresa Alciato en el Emblema XVIII bajo el lema "Los Prudentes" presidido por una cabeza bifronte de Jano y la interrogación retórica: "¿por qué te pintan con tantos ojos y rostros?, ¿Acaso no es porque esta imagen simboliza al hombre precavido?"4. Ripa interpretará la Prudencia como una mujer con dos rostros "a semejanza de Jano", que luce una serpiente enroscada en el brazo y se mira en un espejo como símbolo de la propia cognición. ${ }^{5}$

En los grabados que ilustran las Imagines Deorum de Vicenzo Cartari ${ }^{6}$ encontramos varias representaciones de Jano de cuerpo entero, mostrando en sus manos las cifras "CCC" y "LXV" en alusión a su dominio sobre los días del año, aunque la iconografía que tendrá mayor predicamento es la que presenta a Jano sosteniendo en una mano las llaves del templo, y en la otra la vara, bastón o cetro, con los que ejerce su papel de custodio y guía (fig. 2). De este modo efigiará Luca Giordano a Carlos II en el retrato alegórico de la bóveda desvelada hace unos años en el despacho del rey en Aranjuez ${ }^{7}$.

Juan Cristóbal Calvete de Estrella, responsable de la compra para el príncipe Felipe de más de cinco ediciones de los emblemas de Alciato ${ }^{8}$, en su narración del Felicíssimo viaje (1548-1551) describe el Arco de los españoles levantado en

3 Vid. ENCISO MONZÓN, Juan Francisco, Tradvccion poetica castellana de los doze libros de la Eneida de Virgilio Maron, [...] consagrada a la Catolica Magestad de Carlos Segundo, Cádiz, por Cristoval Requena, 1698, fol. 158.

4 Vid. ALCIATO, Andrea, Emblemas, Edición de Santiago Sebastián, Madrid, Akal, 1993, p. 50.

5 Vid. RIPA, Cesare, Iconología, t. I y II, Madrid, Akal, 2002, pp. 233-237.

6 Vid. CARTARI, Vicenzo, Imagines Deorum, Qui Ab Antiquis Colebantur, Lyon, 1581 (Venecia, 1556).

Vid. SANCHO, José Luis: "Ianus Rex. "Otra cara" de Carlos II y del Palacio Real de Aranjuez: Morelli y Giordano en el despacho antiguo del Rey", en Reales Sitios, $\mathrm{n}^{\circ}$ 154, 2002, pp. 34-45, con documentadas notas acerca de la dimensión cortesana de Jano como emblema de virtud cortesano.

8 Vid. GONZALO SÁNCHEZ-MOLERO, José Luis, La "Librería rica" de Felipe II. Estudio histórico y catalogación, Madrid, Ediciones Escurialenses, 1998, pp. 184-186. 
Amberes en forma de templo de Jano a manera de tabernáculo circular rodeado de obeliscos, en cuyo friso se podía leer una inscripción latina alusiva al príncipe Felipe como heraldo de una nueva era de paz tras el cierre de los umbrales del templo de la guerra. La estatua de Jano bifronte también estaba en el Arco de los genoveses con el elocuente letrero: "Yo soy aquel dios Jano, portero de todo el mundo, muy alto Príncipe don Phelippe, que tantas vezes he abierto la puerta a vuestro padre para tantas y tan esclarecidas hazañas..." Alusiones semejantes se había ido encontrando el príncipe a su paso por Génova, Mantua y Brujas.

Aunque el recurso era ampliamente conocido, es rara la identificación directa del dios pagano de la prudencia con Felipe II tal y como aparece en el grabado de Meisner, cuyo significado emblemático queda expresado a través de dos inscripciones en latín y alemán que actúan de motti bilingües que explican y completan la imagen. Debajo del monumento leemos: "Quod sequitur

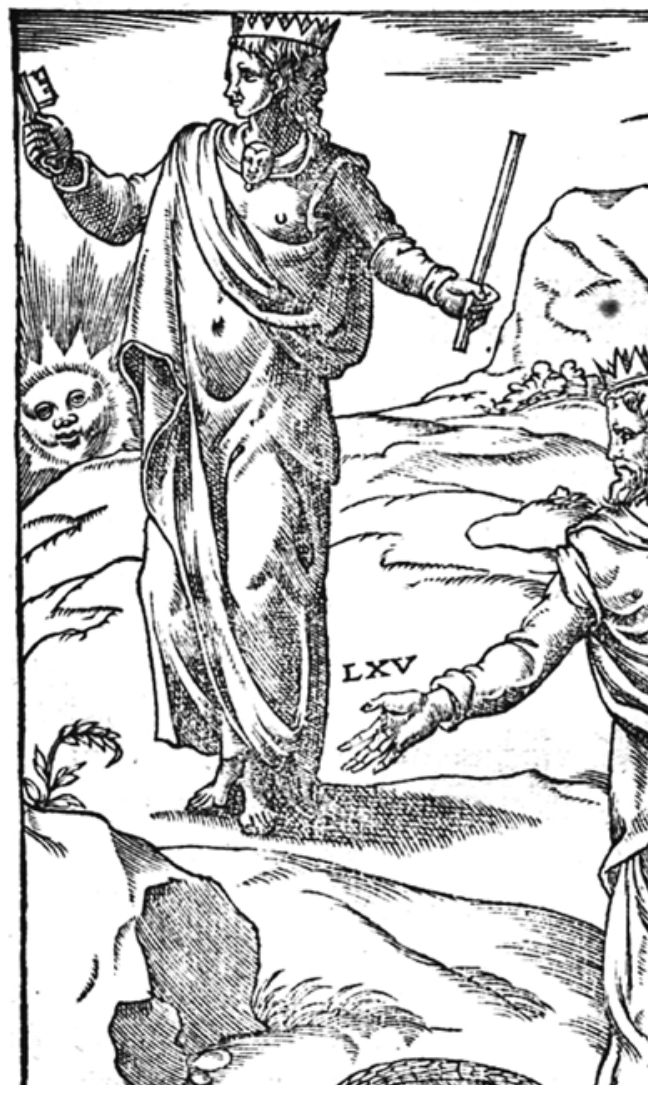

Fig. 2. Vincenzo Cartari, Imagines Deorum, Qui $A b$ Antiquis Colebantur, Lyon, 1581. spectes et praesens ante videto", que a modo de advertencia puede traducirse: "Examina las consecuencias y considera primero las circunstancias presentes". Debajo del rey-dios: "Sectandus cunctis est Deus iste bifrons": "Es necesario que todos (o con todos los medios), se siga a este dios bifronte". El mensaje es aparentemente positivo y de hecho la estampa se ha interpretado como una alegoría encomiástica del buen gobierno de Felipe II simbolizado en la fábrica escurialense, aunque quizá cabría entenderla en clave menos benévola atendiendo al contexto protestante de la publicación y el trasfondo sangriento de la Guerra de los Treinta Años. De hecho el rey-dios de la estampa de Meisner tiene el rostro envejecido hacia ambos lados, el cetro se ha convertido en espada y la llave es un alfanje afilado, lo que otorga al personaje una presencia más

9 Vid. CALVETE DE ESTRELLA, J. C., El Felicíssimo viaje del muy alto y muy poderoso príncipe don Phelippe, Edición de Paloma Cuenca, Sociedad Estatal para la Conmemoración de los Centenarios de Felipe II y Carlos V, 2001, pp. 387-388 y 393-394. 
inquietante que tranquilizadora aunque no por ello necesariamente negativa, acaso en alusión sutil a que las puertas del templo-relicario de los Austrias españoles estaban por entonces abiertas.

La estampa de Meisner nos trae a la mente la más famosa grabada a buril por Perret en 1619 para la obra de Luis Cabrera de Córdoba ${ }^{10}$, en la que de manera similar monumento y patrono sintetizan conceptos e intenciones, en el caso español sin resquicio alguno para la ambigüedad interpretativa. Como es sabido, imágenes y palabras acompañaron desde antes incluso de su terminación al monumento filipino, cargándolo de significados e intenciones, en un proceso que podemos considerar ejercido a posteriori, como si se tratara de un pesado ropaje que el historiador debe "esclarecer", en su afán desmedido por actualizar y clasificar. No obstante, la fábrica literaria es inseparable de la fábrica de cal y canto y genera dos monumentos simultáneos, el real y el imaginado, construcción de piedra y construcción de palabras, ambas con una finalidad compartida: la persuasión del lector, del oyente o del visitante. Una tercera fábrica, aliada de la primera, será la que generen los grabados y estampas, diluyendo, estilizando y corrompiendo el canónico modelo herreriano, apropiación sobre la apropiación del edificio, con resultados imprevisibles.

Estas tres fábricas hacen girar sus mecanismos persuasivos a partir de un principio considerado particularmente barroco: la reiteración. Reiteración de claustros y ventanas, reiteración retórica de tópicos, metáforas y alegorías, acumulación de conceptos, variaciones sobre lo mismo se disponen en el pentagrama de la arquitectura, dosificando significados, sometiendo los conceptos a rígidos principios clasificatorios. Paralela a la jerarquía topográfica del edificio surge una jerarquía retórica ordenadora de contenidos y continentes, generadora de los particulares itinerarios y espacios de la memoria.

Si observamos el emblema 36 de Sebastián de Covarrubias y Orozco (1610) se nos presenta El Escorial descompuesto en piezas, como un jeroglífico de la memoria (fig. 3): templo, muralla, pirámide, mausoleo, el monasterio filipino es cifra de las maravillas de la Antigüedad "que el tiempo a consumido, y a prescrito"11. La filacteria enarbola el conocido lema latino: "Omnis caesareo cedat labor", perteneciente al epigrama I de Marco Valerio Marcial ( 80 d. C.) de su obra Liber spectaculorum, en la que celebra la superioridad del Anfiteatro Flavio sobre todos

10 CABRERA DE CÓRDOBA, Luis, Don Felipe Segvndo. Rey de España al Serenisimo Principe sv nieto esclarecido don Felipe de Austria, Madrid, Luis Sánchez, impresor del Rey, 1619. Para un análisis de la estampa de Perret: PÁEZ (coord.) (1985), op. cit., pp.77-78 y 268. Sobre Cabrera de Córdoba y El Escorial, Vid. SUÁREZ QUEVEDO, Diego, "El Monasterio de El Escorial y sus artífices según una fuente documental coetánea. Datos y juicios del historiador Luis Cabrera de Córdoba”, en Juan de Herrera y su influencia, Actas del Simposio (Camargo, 14/17 julio 1992), Fundación Obra Pía Juan de Herrera, Universidad de Cantabria, 1993, pp. 43-51.

11 COVARRUBIAS OROZCO, Sebastián de, Emblemas morales, Madrid, Luis Sánchez, 1610 (Ed. facsimilar, Madrid, Fundación Universitaria Española, 1978). 


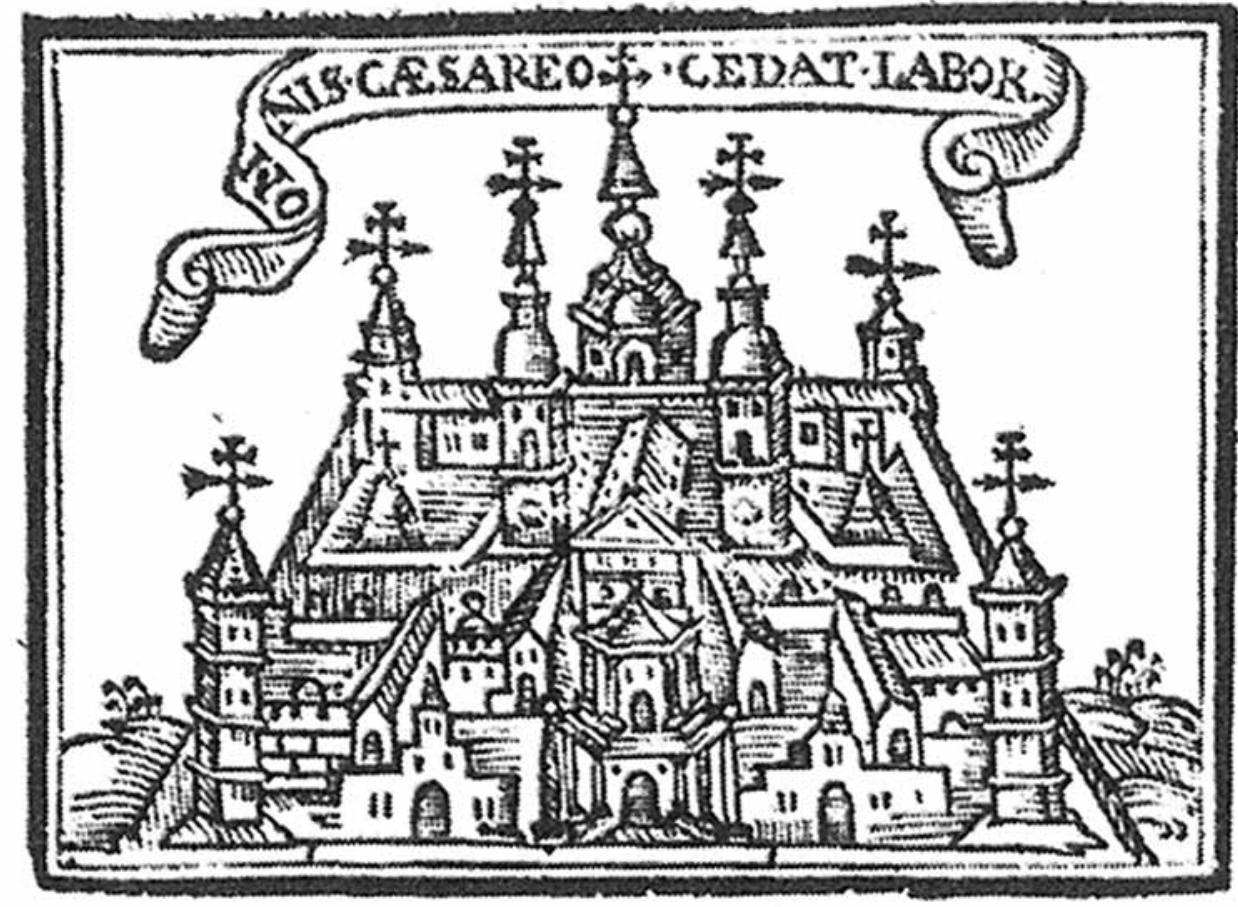

Fig. 3. Sebastián de Covarrubias y Orozco, Emblemas morales, Madrid, 1610.

los monumentos ${ }^{12}$. Fray Francisco de los Santos en el prólogo de su Descripción breve del Monasterio de S. Lorenzo el Real (1657) desgrana de forma elocuente el emblema de Covarrubias completando el epigrama de Marcial: "Omnis Caesareo cedat labor Amphiteatro, Vnum pro cunctis fama loquatur opus" y actualizando intencionadamente su significado, "acomodando el concepto", concluye: "Omnis structurae cedat structura Philippi" "13.

12 José Guillén da la siguiente traducción del epigrama I de Marcial: "No mencione la bárbara Menfis las maravillas de sus pirámides, ni el trabajo asirio se jacte de Babilonia; no se alaben los afeminados jonios con el templo de Diana, que el ara abundante en cuernos deje olvidar a Delos, y que los carios cesen de ensalzar con elogios inmpoderados hasta los mismos cielos el Mausoleo colgado el aire vacío. Toda obra humana debe ceder al anfiteatro del César, la fama celebrará únicamente ésta por todas.” Vid. GUILLÉN, José, Epigramas de Marco Valerio Marcial, Zaragoza, Instituto Fernando el Católico, 2003, p. 65.

13 SANTOS, fray Francisco de los, Descripción breve del Monasterio de S. Lorenzo el Real del Escorial. Vnica Maravilla del Mundo [...] aora nuevamente coronada por el catholico rey Philippo Quarto el Grande, Madrid, Imprenta Real, 1657 (Ed. facsimilar, Madrid, Almiar, 1984), prólogo sin foliar. Que podríamos traducir como "toda estructura debe ceder a la estructura de Felipe". La contestación latina al epigrama de Marcial no es original de Santos, la encontramos ya en la obra del cosmógrafo y topógrafo protestante Martin Zeiller (Itinerarium tinerarium Hispaniae: oder Raiss-Beschreibung durch die Königreich Hispanien und Portugal, Ulm, 1637), Vid. HENERMAN, Theodor, "El Escorial en la crítica estético-literaria del extranjero. Esbozo de una historia de su fama", en Monasterio de San Lorenzo el Real El Escorial en el Cuarto Centenario de su 
La estrategia persuasiva del padre Santos discurre paralela al frontispicio emblemático grabado por Pedro de Villafranca en 1657 que viene a ilustrar el prólogo, en el que otra filacteria enarbola el lema que se pretende definitivo: "Opus miraculum orbis". El detonante para reactivar los viejos y conocidos repertorios de tópicos, es la terminación del Panteón tres años antes, en 1654, por parte de Felipe IV, miraculum intra miraculum ${ }^{14}$ que corona el monumento sellando el significado dinástico del edificio como depósito eterno de la memoria de los Austrias.

Una vez concluidas las ceremonias de Traslación de los Cuerpos Reales a su definitivo depósito en los más hondos cimientos del edificio, comienza la reordenación de las colecciones pictóricas de El Escorial dirigida por Velázquez, el montaje heteróclito y acumulativo que disfrutó Felipe II y describió fray José de Sigüenza desaparece, los loci persisten pero las imagines cambian configurando nuevos recorridos de paredes siempre blancas y marcos dorados ${ }^{15}$ en los que llama la atención la falta aparente de un programa ${ }^{16}$. La temática religiosa enlaza todos los temas pero el criterio que dota por primera vez de coherencia expositiva a espacios como la sacristía o las salas capitulares, no es devocional, sino artístico. Aquella historia paradigmática del arte descrita por Sigüenza en los muros de El Escorial se depura y enriquece presentándose de acuerdo a un nuevo gusto que aúna y confronta a Tintoretto y Tiziano pero también a un supuesto Caravaggio con Annibale Carraci, a Correggio con Guido Reni o a Rubens con Van Dyck.

Como es bien sabido, las pinturas más valiosas donadas por el rey al convento de San Lorenzo procedían de la subasta de la colección de Carlos I de Inglaterra, aquel rey que siendo príncipe rastreó las colecciones escurialenses en busca principalmente de telas de Tiziano, encargando copias de sus obras y adquiriendo incluso

Fundación 1563-1963, Ed. Biblioteca "La Ciudad de Dios”, Real Monasterio de El Escorial, Madrid, 1964, p. 761, (reedición del trabajo aparecido en la revista Escorial, n 32, junio 1943, pp. 319-341).

14 Nos permitimos extrapolar al Panteón la glosa con la que fray Francisco de los Santos corona el altar de la Sagrada Forma en la Sacristía de El Escorial: "En Magni Operis Miraculvm / Intra Miracvlvm Mvndi / Coeli Miracvulo Consecratvm", retablo que "Encargóle Su Majestad la superintendencia de esta fábrica", citado en ANDRÉS, Gregorio de: "Alhajas y mejoras que percibió esta real casa de S. Lorenzo en los seis años del priorato del Rmo. Fr. Francisco de los Santos así en la hacienda como en la fábrica" en La Ciudad de Dios, vol. CLXXX, 1967, p. 136.

15 Como insisten en señalar todos los cronistas jerónimos y anota Julio Chifflet, capellán de Felipe IV, en su relación manuscrita de 1656 refiriéndose concretamente a la sacristía: “[...] las paredes laterales han sido enlucidas [...] Diego Velázquez, pintor y ayuda de cámara de Su Majestad, ha estado varios meses ocupado en disponerlo todo y ha dispuesto labrar marcos dorados para los cuadros." Vid. ANDRÉS, Gregorio de, "Relación de la estancia de Felipe IV en El Escorial (1656) por su capellán Julio Chifflet. Ediciones y notas por el P. Gregorio de Andrés, O.S.A." en Documentos para la Historia del Monasterio de San Lorenzo el Real de El Escorial, vol. VII, 1964, pp. 407 y 409.

16 Para el estudio de las colecciones pictóricas escurialenses en este período son indispensables los trabajos de BASSEGODA I HUGAS, Bonaventura, El Escorial como museo. La decoración pictórica mueble en el monasterio de El Escorial desde Diego Velázquez hasta Frédéric Quilliet (1809), Bellaterra, Barcelona, Girona, Lleida, 2002, y más recientemente: Idem, "Fray Francisco de los Santos y la difusión de la primera gran colección pictórica visitable en España", en La historia imaginada: construcciones visuales del pasado en la Edad Moderna, Centro de Estudios Europa Hispánica, 2008, pp. 267-281. 
los fragmentos recortados por Navarrete de la Santa Cena del cadorino ${ }^{17}$. El 12 de septiembre de 1623 Felipe IV se despedía en El Escorial de Carlos Estuardo y para perpetuar la memoria de aquel encuentro políticamente fallido pero de importantes consecuencias artísticas, mandó erigir en las inmediaciones de la dehesa de Campillo una columna trofeo de cinco metros de altura cuya inscripción latina concluía con el lema "Posteritate sacrum"18.

Treinta y un años después Felipe IV veía colgadas en los muros de la sacristía de El Escorial algunas de las piezas más exquisitas de la colección inglesa, completando los huecos de esa historia del arte que como decimos siempre aspiró al paradigma. Julio Chifflet, capellán francés de Felipe IV refiere el placer sentido por el monarca al contemplar el nuevo montaje: "El Rey, que Dios conserve, estando mejor de salud, fue a ver, al día siguiente la sacristía, nuevamente ornamentada con muy bellas tablas originales de tema religioso que él tenía, las cuales ha enviado a este lugar, diciendo que hace tiempo tenía intención de adornarla con lo más bello que hubiera en este arte, puesto que sus restos van a descansar aquí para siempre." 19

La ciudad de los muertos es necesariamente ciudad de la memoria, depósito cerrado, aquilatado desde la traza universal de Juan Bautista de Toledo, pero cuyo thesaurus de contenidos está abierto desde ese mismo momento a modificaciones y apropiaciones como la ejercida en este caso por Felipe IV. Surge entonces la necesidad de la memoria escrita, del libro que difunda los cambios y satisfaga a la curiosidad estudiosa que habla, comenta, elogia pero también critica el edificio, en el menor de los casos lo visita físicamente. La Descripción breve del padre Santos no surge en el seno de la comunidad religiosa sino que es producto del deseo del rey, también la elección de su autor, el cual tendrá que afrontar la comprometida tarea de reducir a más breve tomo los dos últimos libros de la III parte de la Historia Orden de San Jerónimo, en los que fray José de Sigüenza, discípulo de Arias Montano, había abordado la historia de la fundación y la descripción de las partes de la fábrica ${ }^{20}$.

17 Según refiere DOORT, Abrahan van der, Catalogue of the Collections of Charles I, c. 1639 (Ed. O. Miller, Walpole Society, Glasgow, 1960, vol. 37), Vid. WETHEY, Harold, The Paintings of Titian. Complete Edition. Volume I. The Religious Paintings, London, Phaidon, 1969, nº. 46; RUIZ GÓMEZ, Leticia, Catálogo de Pintura veneciana histórica en el Real Monasterio de El Escorial, Patrimonio Nacional, 1991, p. 86.

18 Vid. ANDRÉS, Gregorio de, "La despedida de Carlos Estuardo, Príncipe de Gales, en El Escorial (1623) y la columna-trofeo que se levantó para perpetua memoria”, en Anales del Instituto de Estudios Madrileños, t. X, 1975, pp. 113-132.

19 Vid. ANDRÉS, Gregorio de (1964), op. cit., pp. 408-409.

20 SIGÜENZA, fray José de, Tercera parte de la Historia de la Orden de San Geronimo Doctor de la Iglesia. Dirigida, Al Rey nuestro Señor. Don Philippe III. Por Fray Ioseph de Siguença, de la misma Orden, Madrid, En la Imprenta Real. Año M.DC.V. Libros III y IV en: La fundación del Monasterio de El Escorial, Madrid, Aguilar, 1963; Madrid, Turner, 1986. Para un estudio completo de la vida y obra del P. Sigüenza: BLASCO CASTIÑEYRA, Selina, El Padre Sigüenza y El Escorial, Tesis inédita, 4 vols., U.C.M., 1999; THOMPSON, Colin, "Reading the Escorial Library: José de Sigüenza and Golden-Age Culture", en Culture and Society in Habsburg Spain, London, Támesis, 2001, pp. 79-93. La edición completa de la Tercera parte 
Existe una diferencia sustancial entre ambas obras ya que la primera sí fue un producto generado desde la comunidad, dispuesto a modo de colofón de su propia historia, y sagazmente elaborado con la intención de llamar la atención de Felipe III en un momento en el que la corte seguía instalada en Valladolid. Pensemos en la intencionalidad con que Sigüenza recuerda el protagonismo del príncipe en la consagración de la basílica o la anécdota del banco del coro compartido con su padre. Las intenciones del libro de fray José surtieron efecto, de hecho como asegura Baltasar Porreño la lectura de sus páginas dejó insomne al rey durante toda una noche: "luego que vino este libro erudito a sus manos, le comenzó a leer después de cena, y se cabó tanto en su lectura, que puniendo treguas al sueño, no le dexó de las manos hasta que vino la mañana, y entró el sol por las vedrieras de su palacio, que le fue motivo para irse a dormir." ${ }^{21}$ La cita ilustra con elocuencia la lectura privada en la intimidad del palacio y nos trae a la mente otro contexto en el que otra descripción intencionada, la de la catedral de Toledo, debía ser leída en voz alta ante el futuro Felipe II, recomendando su autor el canónigo Blas Ortiz: "mande que se lea el capítulo que más sea servido de oír." ${ }^{22}$

Para entender qué implicaba en el siglo XVII "reducir a más breve tomo" cabe analizar la Descripción breve de 1657 desde la preceptiva retórica de su siglo. Fray Francisco de los Santos partirá de la inventio que le proporciona Sigüenza, cuya validez se considera incuestionable. Como primera de las operaciones retóricas, la inventio se define, desde la Rhetorica ad Herennium o la Institutio oratoria de Quintiliano, como el hallazgo de las ideas, será para el Padre Santos el elemento referencial de partida.

A la inventio le sigue la dispositio, en la que fray Francisco de los Santos cumple un papel decisivo, ya que es en esta segunda operación retórica en la que los elementos referenciales se ordenan, cambiando su coherencia dispositiva en función de unas necesidades nuevas. Como señala David Pujante "la dispositio construye el más coherente diseño interpretativo de la causa"23. Santos modifica la dispositio de Sigüenza sirviéndose de las clásicas categorías aristotélicas de supresión, adición, sustitución y cambio de orden. Extiende el discurso de Sigüenza como un rom-

de la Historia de la Orden, con estudio preliminar de Francisco J. Campos y Fernández de Sevilla, en: Historia de la Orden de San Jerónimo, Salamanca, Junta de Castilla y León, Consejería de Educación y Cultura, 2000.

${ }^{21}$ PORREÑO, Baltasar, Museo de los Reyes sabios, que an tenido las Naçiones del orbe: y los libros que ellos, y los Emperadores, y Infantes han escrito y sacado a luz [...], fol. 20 (BNE, Mss. 2297), citado en BLASCO CASTIÑEYRA, Selina (1999), op. cit., t. III, p. 266.

${ }_{22}$ Se trataba del ejemplar manuscrito e iluminado enviado por Blas Ortiz al príncipe Felipe de su obra: Summi Templi Toletani graphica descriptio (Archivo General de Simancas, Estado, leg. 8.335, $\mathrm{n}^{\mathrm{o}} 128$ ), citado en SÁNCHEZ-MOLERO, Gonzalo (1998), op. cit., p. 77.

${ }_{23}$ PUJANTE, David, "La operación dispositio como base de la construcción del significado discursivo", en Tonos. Revista electrónica de estudios filológicos, $\mathrm{n}^{\circ}$ 5, 2003. Sobre retórica, Vid. RICO VERDÚ, José, La retórica española de los siglos XVI y XVII, Madrid, Consejo Superior de Investigaciones Científicas, 1973; AZAUSTRE, Antonio, CASAS, Juan, Manual de retórica española, Barcelona, Ariel, 1997; ALBADALEJO, Tomás, Retórica, Madrid, Síntesis, 1993. 
pecabezas que reconstruye con otro orden, elimina lo que considera inapropiado, pensemos en las iras furibundas de Sigüenza hacia Federico Zuccari, y abre huecos en donde va introduciendo nuevos elementos que irán aumentando en cada edición. Si nos dedicamos a descomponer a la inversa el proceso, nos encontraremos un rastro de puntos y comas y signos ortográficos que testimonian los movimientos de fragmentos como si se tratara de un collage de palabras.

Según Quintiliano la dispositio es la operación retórica que menos se puede enseñar ya que pertenece a la capacidad natural de cada persona, es decir al propio talento para percibir y comprender la causa (ingenium), es lo que impide que la dispositio consista en una simple diseminación por el discurso de recursos estilísticos. No pretendemos juzgar aquí el talento poético del padre Santos, simplemente reconstruir su método. La dispositio empleada por Sigüenza es de carácter interpretativo, Quintiliano recomienda siguiendo a Celso y Cicerón, que primero hemos de colocar los argumentos sólidos, en último lugar los muy sólidos, en medio los que tienen menos fuerza. Sigüenza deja para el final del recorrido aquello que considera más importante, la descripción del templo, Santos en cambio opta por colocarla al principio precisamente por la misma causa, su estrategia ordenadora es más persuasiva que interpretativa sencillamente porque no necesita justificar el objeto del discurso.

Una vez hallados los elementos del discurso y reordenados de forma coherente llegamos a la tercera de las operaciones retóricas, la elocutio, que consiste en expresar verbalmente todo el material de manera elegante y convincente. Pongamos un ejemplo, fray José de Sigüenza menciona entre las reliquias de Nuestra Señora: "[...] un poco de lienzo que dice el testimonio que vino con él es reliquia de aquel con que enjugaba los ojos cuando estaba al pie de la Cruz ayudando con sus lágrimas al rescate del linaje humano como mejor podía, que, aunque el precio era harto cumplido, por ser la sangre de valor infinito, también esta agua la aplica Dios y la incorpora, digámoslo así, para que entre en el tesoro." ${ }^{24}$ Fray Francisco de los Santos en el mismo punto, abrevia, suprime, trastoca y añade: "vn poco del lienço, con que se enjugaua los ojos al pie de la Cruz, quando juntandose aquel Aljofar de la Aurora con los Rubies del Sol, en su Occidente, se incorporauan en el Tesoro de nuestro rescate." 25

La elocutio de Santos le aproxima curiosamente a un autor tan aparentemente alejado como don Juan de Tassis, Conde de Villamediana, autor también de una descripción en su comedia De la Gloria de Niquea, y descripción de Aranjuez, representada en el Real Sitio de Aranjuez con motivo del cumpleaños de Felipe IV el 18 de abril de 1622. La obra fue interpretada por la misma reina Isabel de Borbón, la infanta María y sus damas, en la que el mes de abril saluda al Tajo con

\footnotetext{
24 SIGÜENZA, fray José de, 1605 (1986), op. cit, L. IV, D. XVI, pp. 359-360.

25 SANTOS, fray Francisco de los, 1657 (1984), op. cit, L. I, D. VIII, fols. 36 v-37.
} 
estos versos: "[...] El mejor anbar de la Primavera / Bordò el mejor aljofar de la Aurora; $[\ldots]{ }^{\prime 26}$ El ejemplo nos permite colocar la elocutio de Santos, es decir su estilo, en el terreno del regocijo cortesano, ya que de las tres cualidades elocutivas, que son puritas (corrección gramatical), perspicuitas (grado de comprensibilidad del discurso), es el ornatus, la que parece interesar más a nuestro autor, es decir el embellecimiento verbal del discurso. Podemos resumir diciendo a grandes rasgos que fray Francisco de los Santos partiendo de la inventio de Sigüenza, altera su dispositio y genera una nueva elocutio de resonancias cortesanas.

En definitiva es la vinculación con la corte el elemento que caracteriza y hace singulares a los jerónimos de entonces frente a las demás órdenes religiosas. Si enumerásemos la lista de tópicos negativos (glotonería, despilfarro, apatía cultural...) recapitulados por los rétores desamortizadores que justificarán la disolución posterior de la orden, comprenderemos que la existencia de los monjes de San Jerónimo parecía solo posible desde su privilegiada y secular proximidad a la corte, haciendo inviable su permanencia más allá del Antiguo Régimen.

El 11 de mayo de 1636, con apenas veinte años, Francisco de la Plaza profesaba en el monasterio jerónimo de San Lorenzo el Real como fray Francisco de los Santos. Según cuenta su memoria sepulcral2 ${ }^{27}$, recibió los primeros rudimentos en la Gramática siendo niño cantor en el monasterio de San Bartolomé de Lupiana, casa madre de la orden. Después pasó a Alcalá de Henares en donde se formó en el "primor de la Rethorica" destacando de tal manera que durante su año de noviciado, en las buhardillas de San Lorenzo ya daba muestras grandes de "entendido". Sus cualidades le hicieron merecedor de una de las codiciadas plazas del Colegio, en donde "se aplico con mas veras a las Letras", dando forma a aquel innato y "singular numen poético que diuertia y no molestaua". Quizá sea ésta última frase la que mejor sintetiza lo que hizo extraordinario entonces a aquel muchacho hijo de labradores que conseguiría escalar todos los puestos posibles en la jerarquía colegial y conventual hasta ser nombrado por Carlos II en tres ocasiones prior de San Lorenzo el Real. Dicho cargo recordemos que suponía, entre otras cosas, la superintendencia teórica o real de todas las obras, reformas y reparaciones, en definitiva el dominio feudal y absoluto sobre el edificio y su territorio.

Murió el 14 de junio de 1699, pasados los ochenta y dos años en su alcoba aneja a la torre del Prior pudiéndose jactar de haber sacado a luz uno de los escasísimos

26 TASSIS, Juan de, De la Gloria de Niquea, y descripción de Aranjuez, en Obras de Don Iuan de Tarsis Conde de Villamediana, Correo Mayor de Sv Magestad. Recogidas por el Licenciado Dionisio Hipolito de los Valles. Al Excelentissimo Señor Conde de Lemos, \& c. Con Licencia, y privilegio. En Çaragoça, por Iuan de Lanaja y Quartaner Impresor del Reino de Aragon, y de la Vniversidad, Año 1629. A costa de Iuan de Bonilla Mercader de Libros, fol. 8.

27 Para la memoria sepulcral de fray Francisco de los Santos, Vid. PASTOR, Fernando, Las Memorias sepulcrales de los Jerónimos de San Lorenzo del Escorial, Madrid, Ediciones Escurialenses, 2001, pp. 314316. 
libros españoles de "arte" que había sido "estimado en todo el mundo", con cuatro ediciones consecutivas y aumentadas $(1657,1667,1681,1698)$ que circularon por toda Europa y América y una traducción al inglés (1671) auspiciada por el Duque de Sandwich que interesó al mismísimo Samuel Pepys ${ }^{28}$.

Desde Solino, Quintiliano, Cicerón y la Retórica ad Herenium, la memoria ha sido considerada la cuarta operación de la Retórica, después de la inventio, dispositio y elocutio y precediendo a la locutio. Su arte implica la distinción entre una memoria natural innata y otra artificial generada por el hombre a través de la creación de loci e imagines, lugares asociados con imágenes. Para que el mecanismo funcione se recurre siempre al símil arquitectónico, imaginar un edificio conocido, en el que cada puerta nos conduce a un concepto, el orden es fundamental pues de él depende el método mnemónico que estructura las partes del discurso.

Después de San Agustín, para el cual la memoria ofrecía la posibilidad de abarcar el universo entero, los escolásticos, comenzando por San Alberto Magno otorgaron a la memoria un valor moral asociado a la previsión y la prudencia ya que el hábito de recordar las cosas del pasado capacitaba para actuar con rectitud en el futuro: "de todas las cosas que forman parte de la prudencia ninguna es más necesaria que la memoria, porque a partir de las cosas pasadas somos dirigidos hacia las presentes y las futuras" 29 . En el desarrollo de su método, el sabio dominico huirá de las construcciones imaginarias aconsejando centrarse en lugares memorísticos reales, siendo los más adecuados los "solemnes y raros", aconsejará además, entre otras cosas, que estén situados en parajes tranquilos y que los intervalos que los constituyan sean moderados, en concreto "de unos treinta pies"30.

Santo Tomás, discípulo de Alberto Magno, aborda el tema de la memoria en el epígrafe correspondiente a la "Prudencia" de la Summa Theologiae, en donde desarrolla su concepto de phantasmata para definir aquellas imágenes intelectivas que necesariamente debemos generar para poner en marcha la maquinaria de la memoria artificial. La memoria cristiana genera phantasmata y se recrea en las imágenes de vicios y virtudes, explotando sus posibilidades devocionales, el salto lógico nos llevaría a la composición de lugar jesuítica y al castillo interior de Santa Teresa ${ }^{31}$ pero quedémonos en el método escolástico de Santo Tomás, pues es éste el engranaje fundamental del sistema educativo del Colegio jerónimo de San Lorenzo. Quizá no sea del todo aleatorio que la

28 Vid. VEGA-LOECHES, José Luis, "Sobre la primera traducción al inglés de la Descripción breve de El Escorial de Francisco de los Santos. Lately consumed by fire (1671), del entorno del conde de Sandwich", en Anales de Historia del Arte, 19, 2009, pp. 181-194.

${ }^{29}$ Citado en YATES, Frances A., El arte de la Memoria, Siruela, Madrid, 2005 (1966), p. 87.

30 YATES, Frances A. (1966), op. cit., p. 84. Entre los libros comprados por Calvete de Estrella en Salamanca para el príncipe Felipe figuran catorce ejemplares con las obras del sabio alemán (beatificado en 1622 y canonizado en 1931) entre otras su De Memoria et Reminiscentia (Venecia, 1510) que aún se conserva en la Real Biblioteca (M. ${ }^{\text {9 } 9-I-7) ~ V i d . ~ S A ́ N C H E Z-M O L E R O, ~ G o n z a l o ~(1998), ~ o p . ~ c i t ., ~ p p . ~ 176-182 . ~}$

31 Vid. RODRÍGUEZ DE LA FLOR, Fernando, Teatro de la Memoria. Siete ensayos sobre mnemotecnia española de los siglos XVII y XVIII, Salamanca, Junta de Castilla y León, 1988. 
primera piedra "del losado"32 de la Basílica, "en donde se había de señalar la planta"33, se colocara el día de Santo Tomás de 1575, la cuestión es que el saber del aquinate circulaba por el monasterio compilado en tablas retóricas que con ingenio permitían optimizar la memorización de sus conceptos. Cuenta fray José de Sigüenza que el tercer prior de San Lorenzo, el culto fray Hernando de Ciudad Real "entendió a Aristóteles tan bien como cualquiera de su tiempo, y como tenia largo ingenio, se divirtió a estudiar música y tecla y aun poesía, ... estudió también matemáticas y puso las partes de Santo Tomás de Aquino en una disposición de tablas harto ingeniosamente"34

Cuando después del incendio de 1744, un pintor mediocre como Francisco Llamas, acometa la tarea de decorar el techo del paraninfo del Colegio de San Lorenzo con un gran lienzo (fig. 4), el tema elegido no podrá ser otro que la traslación en imágenes de la Summa de Santo Tomás. Así nos lo cuenta fray Andrés Ximénez en su Descripción de 1764: "La idea que se siguió en esta Pintura, fue significar en el

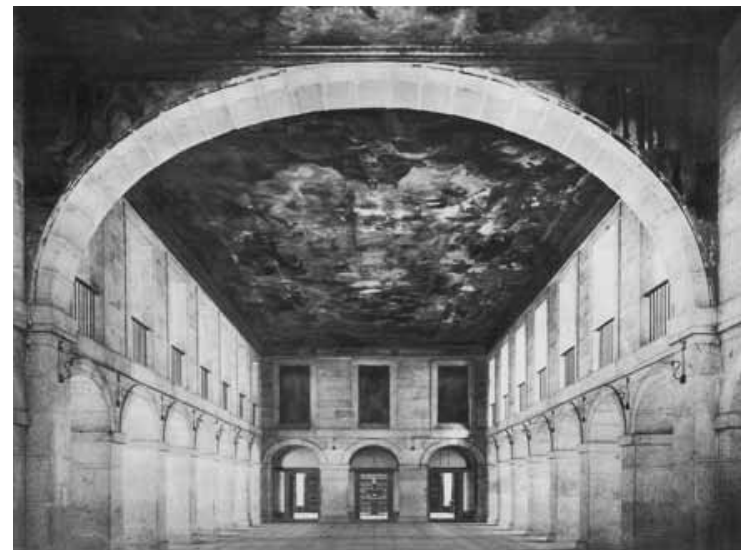

Fig. 4. Vista del "passo" o paraninfo del Colegio de San Lorenzo el Real de El Escorial.
Lienzo las materias mas principales de que trata Santo Tomás (cuya Doctrina se profesa, y venera en este Colegio) para que asi pudiese gozar la vista, lo que el entendimiento toca en estas Aulas con las luces de la razon y discurso." ${ }^{35}$

Tablas ingeniosas e imágenes que visualizan lo que el entendimiento toca, la memoria como ars rethorica ordena y distribuye el conocimiento escolástico del colegio de San Lorenzo, otorga al colegial una estrategia de aprendizaje e instrumenta el discurso

32 Vid. SAN JERÓNIMO, fray Juan de, Memorias, en SALVÁ, Miguel, SAINZ DE BARANDA, Pedro, Colección de Documentos inéditos para la Historia de España, t. VII, Madrid, Imprenta de la Viuda de Calero, 1845 (Ed. facsimilar Patrimonio Nacional, 1984), pp. 121-122.

33 SIGÜENZA, fray José de, 1605 (1986), op. cit., L. III, D. VIII, p. 55.

34 Ibid., p. 53. La fuente de fray José es de nuevo fray Juan de San Jerónimo, el cual también recuerda la singularidad de esas "tablas" ingeniosas en su necrológica de fray Hernando de Ciudad de Real: "[...] fue uno de los que en su tiempo entendieron bien a Aristóteles, y trabajó mucho en este filósofo. En S. Tomás hizo algunos trabajos ingeniosos. Redujo toda la doctrina y conclusiones de sus partes a cierta manera de tablas, que se estimaron en mucho [...]", citado en MODINO DE LUCAS, Miguel, Los priores de la construcción del Monasterio de El Escorial, vol. II, Madrid, Patrimonio Nacional, 1985, p. 9.

35 XIMÉNEZ, fray Andrés, Descripción del Real Monasterio de San Lorenzo del Escorial, Madrid, Imprenta de Antonio Marin, 1764 (Ed. facsimilar, Maxtor, 2006), p. 151. Sobre la pintura de Llamas, posiblemente inspirada en el proyecto no realizado de Vicente Carducho para las Aulas de Teología y Artes, Vid. MODINO DE LUCAS, Miguel, "El gran lienzo del Paraninfo", en Anuario del Real Colegio de Alfonso XII, Madrid, Real Colegio Alfonso XII, Real Monasterio de El Escorial, 1983, pp. 531-580. 
del catedrático y del predicador. Parece lógico pensar que similares recursos mnemónicos estuvieran en la base ordenadora de los contenidos del monasterio, aquilatada en la nueva dispositio de fray Francisco de los Santos. La memoria es el instrumento que permite descifrar el edificio y nos capacita para recorrerlo-recordando los lugares de las pinturas y sus significados.

Para concluir este recorrido apresurado por las implicaciones de la memoria en la fundación filipina, nos gustaría traer a colación dos cuestiones que paradójicamente se conectan en el tiempo y cuya presencia dentro de los muros de El Escorial quizá no sea solamente fruto de la casualidad. En 1576, al año siguiente de colocarse la primera piedra de la planta de la Basílica, Felipe II entrega al monasterio procedente de la biblioteca de Diego Hurtado de Mendoza, el libro de la memoria más famoso de su siglo, L'Idea del Theatro de Giulio Camillo. El ejemplar, hoy desaparecido, estaba ilustrado con "201 hojas de pintura de aguadas en pergamino y de mano del Ticiano" y venía acompañado de "otro libro impreso en italiano en octavo, que es declaración de las pinturas." ${ }^{\prime 36}$ Probablemente se trataba de la primera edición impresa en Florencia en 1550, seis años después de la muerte de Camillo, codificada por su discípulo Girolamo Muzio, auspiciada por Alfonso de Ávalos, marqués del Vasto y dedicada a Diego Hurtado de Mendoza. En ella se ponía por escrito el funcionamiento de aquel teatro memorístico construido para el rey de Francia que presumía de compilar en sus gradas la "idea de una memoria orgánicamente entrelazada con el universo" ${ }^{37}$.

Fray Francisco de los Santos en la segunda edición de la Descripción breve de 1667 sitúa en la llamada "Quadra al mediodía" del Palacio de El Escorial una pintura que no volverá a citar en las ediciones posteriores, un "original valiente de Ticiano, en que se representa el Marques de Pescara haciendo platica a sus soldados, y animandolos, con tan valor, y viueza, que aun pintado, infunde a los que le ven, valentia, y animo."38 $\mathrm{Se}$ trata de la Alocución del marqués del Vasto (Museo del Prado) pintado por Tiziano para Alfonso de Ávalos entre 1540 y 1541 (fig. 5) y adquirido por Felipe IV en la almoneda de Carlos I de Inglaterra ${ }^{39}$. Su presencia en la sala destinada tradicionalmente a audiencias no parece meramente decorativa, sobre todo si atendemos al significado de la pintura como la puesta en escena de las cuatro partes de la retórica que vienen a confluir

36 Vid. ANDRÉS, Gregorio de, Real Biblioteca de El Escorial, Madrid, Aldus, 1970, p. 53.

37 YATES, Frances A. (1966), op. cit., p. 68.

${ }_{38}$ SANTOS, fray Francisco de los, Descripción breve [...] dedicada a la Catolica, y Real Magestad de la Reyna nuestra Señora Doña Maria Ana de Austria, Madrid, Por Ioseph Fernandez de Buendia, 1667, fol. $100 \mathrm{v}$.

39 Vid. LOOMIE, Albert J.: "New Light on the spanish ambassador's purchases from Charles I's collection 1649-1653", en Journal of the Warburg and Cortauld Institutes, 52, 1989, p. 261; PANOFSKY, Erwin, Tiziano. Problemi di iconografia, Venezia, Marsilio, 1992 (New York, 1969), pp. 75-80; CHECA, Fernando, Tiziano y la monarquía hispánica, Madrid, Nerea, 1994, pp. 270-271; SUÁREZ QUEVEDO, Diego, "Tiziano y los venecianos en El Escorial", en El Monasterio del Escorial y la Pintura, Actas del Simposium (1/5-IX2001), Instituto Escurialense de Investigaciones Históricas y Artísticas, San Lorenzo de El Escorial, 2001, pp. 67-98; BASSEGODA I HUGAS, Bonaventura (2002), op. cit., p. 226; FALOMIR, Miguel, "La alocución del marqués del Vasto", en Tiziano, catálogo de la exposición, Museo Nacional del Prado, 2003, pp. 186-189. 


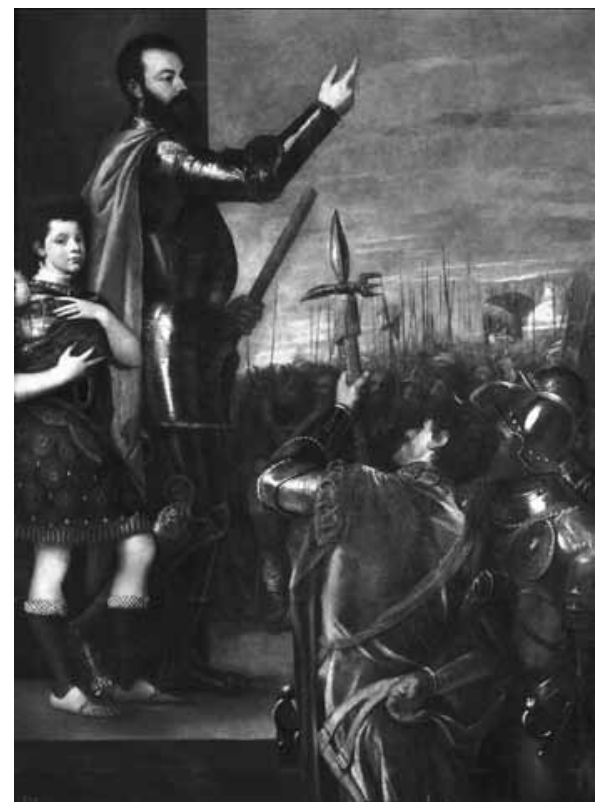

Fig. 5. Tiziano, Alocución del marqués del Vasto a sus soldados, 1540-1541, Museo del Prado. Cat. $n^{\circ} 417$. Inv. Gen. $n^{\circ} 821$. en la actio o pronuntiatio ante un auditorio, la quinta y última de las operaciones retóricas.

Cabría preguntarnos si la Descripción breve de fray Francisco de los Santos implicaba una pronuntiatio, si de la concatenación rítmica de fragmentos se puede deducir una exposición pública de los mismos que dotara de contenidos a las tradicionales visitas al monumento. Una de las más hermosas y esclarecedoras definiciones de escritura nos las proporciona Pedro de Navarra Labrit en sus Diálogos de la differencia del hablar al escribir (1565) cuando afirma que: "un retrato en acto de la habla e una fama de las palabras que queda después que as hablado o una imagen o vida que inmediate que la vees te traerá a la memoria lo que representa, como el pintor que pinta la figura que quien facilmente se conoce por ella" 40

Lina Bolzoni comienza su libro La estancia de la Memoria ${ }^{41}$ recordando una conversación entre Alfonso Dávalos y Girolamo Muzio, discípulo y custodio de la memoria de Camillo. En un momento dado el marqués echa en cara al poeta: "tú pones alas a los vientos, y los pintores los pintan", y para hacer más explícita la imagen que tenía en mente hinchó los carrillos. Más de un siglo después fray Francisco de los Santos recurrirá a la misma imagen, que aún hoy perdura en nuestra mente, al diseñar las escenografías de su Auto de Navidad Los efectos del placer (1680) representado seguramente en el paraninfo del Colegio de San Lorenzo el Real, en cuyo manuscrito anota: "aparecerán los vientos pintados en cartón grandes, hinchados los carrillos como soplando, auna parte y otra al modo que se pintan en los Mapas, y salen al mesmo tiempo el Pesar, y el Alboroto, y suena la Caja y Sordina." 42

40 Citado en BOUZA, Fernando, Comunicación, conocimiento y memoria en la España de los siglos XVI y $X V I$, Salamanca, Sociedad Española de Historia del Libro, Sociedad de Estudios Medievales y Renacentistas, 1999, p. 27

${ }^{41}$ BOLZONI, Lina, La estancia de la memoria. Modelos literarios e iconográficos en la era de la imprenta, Madrid, Cátedra, 2007, pp. 9-10.

42 SANTOS, fray Francisco, auto de Navidad (1680): Los Efectos del Placer, fol. $71 \mathrm{v}^{\mathrm{o}}$ (BNE, Mss. /16063). 